\title{
POTENTIAL PHOSPHORUS EUTROPHICATION MITIGATION STRATEGY: BIOCHAR CARBON COMPOSITION, THERMAL STABILITY AND PH INFLUENCE PHOSPHORUS SORPTION
}

Ngatia L.W., Y.P. Hsieh, D. Nemours, R. Fu and R. W. Taylor

\section{ABSTRACT}

Phosphorus (P) eutrophication is a major pollution problem globally, with unprecedented amount of $\mathrm{P}$ emanating from agricultural sources. But little is known about the optimization of soil-biochar P sorption capacity. The study objective was to determine how biochar feedstocks and pyrolysis conditions influences carbon (C) thermal stability, $\mathrm{C}$ composition and $\mathrm{pH}$ and in turn influence the phosphorus sorption optimization. Biochar was produced from switchgrass, kudzu and Chinese tallow at 200, 300, $400,500,550,650,750{ }^{\circ} \mathrm{C}$. Carbon thermal stability was determined by multi-element scanning thermal analysis (MESTA), C composition was determined using solid state ${ }^{13} \mathrm{C}$ NMR. Phosphorus sorption was determined using a mixture of $10 \%$ biochar and $90 \%$ sandy soil after incubation. Results indicate increased $\mathrm{P}$ sorption $(P<0.0001)$ and decreased $\mathrm{P}$ availability $(P<0.0001)$ with increasing biochar pyrolysis temperature. However, optimum $\mathrm{P}$ sorption was feedstock specific with switchgrass indicating $\mathrm{P}$ desorption between $200-550{ }^{\circ} \mathrm{C}$. Phosphorus sorption was in the order of kudzu> switchgrass $>$ Chinese tallow. Total C, C thermal stability, aromatic C and alkalinity increased with elevated pyrolysis temperature. Biochar alkalinity favored $\mathrm{P}$ sorption. There was a positive relationship between high thermal stable $C$ and $P$ sorption for Kudzu ( $r=0.62 ; P=0.0346)$ and Chinese tallow $(r=0.73 ; P=0.0138)$. In conclusion, biochar has potential for $\mathrm{P}$ eutrophication mitigation, however, optimum biochar pyrolysis temperature for $\mathrm{P}$ sorption is feedstock specific and in some cases might be out of $300-500{ }^{\circ} \mathrm{C}$ temperature range commonly used for agronomic application. High thermal stable $\mathrm{C}$ dominated by aromatic $\mathrm{C}$ and alkaline $\mathrm{pH}$ seem to favor $\mathrm{P}$ sorption.

Key words: Biochar, Carbon, Eutrophication, Mitigation, pH, Phosphorus 


\section{INTRODUCTION}

Phosphorus (P) eutrophication is a growing concern globally (Villapando and Graetz, 2001). Phosphorus is an important nutrient in terms of plant nutrition (Lambers et al., 2008), however, its contribution to underground water contamination and water bodies' eutrophication remains a major problem (Meinikmann et al., 2015; McDowell et al., 2015). Considerable amount of phosphorus translocated to groundwater and surface water bodies emanate from agricultural practices (Dari et al., 2016; Kleinman et al., 2015; McDowell et al., 2015; Schindler et al., 2016; Sharpley et al., 2015; Ulrich et al., 2016). For example, sources of P in agricultural land include; livestock production through fecal matter and urine (Leip et al., 2015) fertilizer application for crop production (Bergström et al., 2015; Ulrich et al., 2016), manure application for crop production (Withers et al., 2016). This necessitates comprehensive consideration of P management options and mitigation measures in agricultural fields to achieve downstream and groundwater P reductions (Dari et al., 2015: Kleinman et al., 2015; Sharpley et al., 2015).

To enhance $\mathrm{P}$ eutrophication mitigation, $\mathrm{P}$ retention and slow release in agricultural fields is important (Siddique and Robinson, 2004). Phosphorus undergoes different geo-chemical processes in soil such as solubilization, complexation, adsorption and precipitation that influences P mobility and fate (Chintala et al., 2013). The soil acidity and alkalinity is a major factor influencing the above properties as they influence $P$ retention and release. In acidic soils $\mathrm{P}$ is fixed by sorption surfaces such as oxides and hydroxides of $\mathrm{Al}$ and Fe through the formation of insoluble $\mathrm{Al}$ and Fe phosphates by ligand exchange and precipitation reactions (Lindsay, 
1979; Sample et al., 1980). While in alkaline soil conditions, P low solubility is caused by formation of metal complexes such as Ca-P and Mg-P (Amer et al., 1985; Marschner, 1995). In addition, soil organic matter (SOM) has been indicated to improve $\mathrm{P}$ sorption and limit $\mathrm{P}$ leaching (Debicka et al., 2016).

In Florida, the majority of soils are sandy or have sandy surfaces, making concern about environmental fate of $\mathrm{P}$ more conspicuous due to groundwater pollution (Villapando and Graetz, 2001). Sustainable agriculture practices in sandy soil generally face large constraints due to low nutrient retention capacity. Excessive leaching and loss of P from agricultural land has been reported to cause contamination of groundwater as well as eutrophication in the water bodies (Carpenter, 2008; Chintala et al., 2014; Sharpley, 2000). However, recent studies have indicated that biochar can affect nutrient retention in arable soils (Uzoma et al., 2011), potentially improving nutrient retention and plant production as well as reducing groundwater contamination and water bodies' contamination (Chen et al., 2010; Dari et al., 2016).

Biochar pyrolysis, a carbonization technology which converts biomass thermochemically into stable, recalcitrant organic carbon (C) compounds that can serve as nutrient carriers to be applied as fertilizer for agricultural soils (Glaser et al., 2015). In addition, emerging thermochemical production of bioenergy produces biochar as a solid coproduct (Nelson et al., 2011) enhancing biochar availability. Biochar recalcitrant organic C exhibits strong sorption affinity for contaminants, organic compounds as well as heavy metals (Cabera et al., 2011; Cao et al., 2009; Zheng et al., 2010). However, biochars has variable properties and reactivity when added to soils due to different feedstocks and pyrolysis processes (Lehmann et al., 2006). Some of the biochar properties that are dependent on pyrolysis temperature and feedstock include 
pH, specific surface area and recalcitrance (Kloss et al., 2012; Mukherjee et al., 2011; Zhao et al., 2013) and consequently they influence biochar reactivity. Hence the need to determine the optimum biochar production process that meets the specific biochar applications, in this case $\mathrm{P}$ sorption.

Application of biochar may be an effective agronomic remedial tool to reduce the $\mathrm{P}$ transport from vulnerable catchments of a landscape (Chintala et al., 2014). Total phosphorus has been reported to be concentrated in biochar and also to increase with increasing pyrolysis temperature (Gaskin et al., 2008; Park et al., 2015). However, phosphorus solubility and availability for translocation is poorly understood. Biochar $\mathrm{P}$ is mainly found in the ash fraction, with $\mathrm{pH}$-dependent reactions controlling its solubilization (DeLuca et al., 2009). Biochar $\mathrm{P}$ sorption is reported to be dependent on feedstock type (Chintala et al., 2014). However, findings on the influence of soil pH on biochar P sorption conflicts with Chintala et al., (2014) report of reduced sorption in acidic soils while Xu et al. (2014) reported increased P sorption in acidic soils and Nelson et al. (2011) indicated decreased phosphate adsorption. In addition using biochar produced from different feedstocks and at different pyrolysis temperature Uzoma et al., (2011) indicated that biochar did not affect P retention capacity and Madiba et al., (2016) suggested that biochar is not a mitigating strategy to decrease $P$ leaching. These contrasting findings suggest that more research needs to be done to determine the factors and optimum conditions that enhance P sorption in sandy soils. Therefore, the objective of this study is; (1) To determine the influence of biochar pyrolysis temperature on optimization of P sorption, (2) To determine the relationship between biochar carbon composition and $\mathrm{pH}$ to $\mathrm{P}$ sorption as influenced by biochar pyrolysis temperature 


\section{MATERIAL AND METHODS}

Biochar was produced from three different feedstocks namely Panicum virgatum (switchgrass) which is a perennial bunchgrass commonly used as a feedstock for biomass energy production, Pueraria montana (Lour.) Merr. (kudzu) which is a perennial vine native to Asia and invasive to Southern USA causing devastating environmental consequences (Sage et al., 2009) and Triadica sebifera (chinese tallow) which is native to Asia and invasive in Southeastern United States useful in biodiesel production (Jubinsky and Anderson, 1996). The three feedstocks were selected because biochar can be produced as a by-product or from a by-product of the primary product or the plant used in biochar production would also lead to additional environmental protection/benefits. Switchgrass is used for anaerobic biomass energy production where biochar is produced as a by-product. Chinese tallow is used for biodiesel production and the by-product can be used for biochar production. Kudzu is an invasive species in Southeastern USA that have been difficult to eradicate and making biochar with the kudzu could be an economically beneficial way of eradication it. Feedstocks were dried at $60^{\circ} \mathrm{C}$ to constant weight before the pyrolysis process. Biochar was produced at $200,300,400,500,550,650$ and $750^{\circ} \mathrm{C}$ under anaerobic condition. This $200-750{ }^{\circ} \mathrm{C}$ pyrolysis temperature range has been commonly used in agronomic biochar production (Chen and Chen, 2009; Zhao et al., 2013). Biochar was produced anaerobically in small batches via slow pyrolysis in a Thermcraft S-Line Single-Zone Split Tube Furnace using a $2 \mathrm{~cm}$-diameter quartz tube fitted with airtight connectors as the pyrolysis chamber (Thermcraft inc., Wiston-salem, NC USA). Approximately $10 \mathrm{~g}$ of feedstock was inserted into the center of the pyrolysis tube and heated at a rate of $10^{\circ} \mathrm{C}$ per minute to 
desired/final temperature, and held at the final temperature for 30 minutes (The desired/final temperature in this experiment were $200,300,400,500,550,650$ and $750^{\circ} \mathrm{C}$, these are the temperatures at which we produced the biochar). The quartz tube was maintained under continuous nitrogen gas flow during the heating and cooling process to prevent oxidation of the biomass. Biochar was ground using the pestle and mortar and stored in scintillation vials.

\section{Feedstock, biochar and biochar+ soils chemical analysis}

Feedstock total metals, iron ( $\mathrm{Fe}$ ), aluminum (Al), magnesium (Mg), calcium ( $\mathrm{Ca}$ ) and potassium (K) were determined by ignition at $550{ }^{\circ} \mathrm{C}$ followed by extraction in $1 \mathrm{M} \mathrm{H}_{2} \mathrm{SO}_{4}$ acid and detection by ICP-MS analysis were done on a X7 Series CCT ICP-MS Thermo Electron Corporation, (Winsford, UK) equipped with a PFA-100 MicroFlow Nebulizer (Elemental Scientific Inc., Omaha, NE) fitted to a Scott-type double pass chilled spray chamber, and with Platinum Sampler and Micro Skimmer cones (Thermo Electron Corporation, Winsford, UK).

Biochar $\mathrm{pH}$ was determined after shaking $1 \mathrm{~g}$ biochar in $20 \mathrm{ml}$ deionized water for 1.5 hours (Rajkovick et al., 2012). Ash content of the feedstock and biochar was determined by heating oven-dried samples in a muffle furnace for 4 hours at $550^{\circ} \mathrm{C}$. Available $\mathrm{P}$ (water extractable) was determined whereby biochar at a ratio of 1:200 (biochar to water ratio) was shaken end-overend in distilled water for $2 \mathrm{~h}$. The supernatant was centrifuged at a relative centrifugal force (RCF) of $2500 \times \mathrm{g}$ for $20 \mathrm{~min}$ and filtered first through a Whatman 41 filter paper and then through a $0.45 \mu \mathrm{m}$ filter paper (Self-Davis and Moore, 2000). Available P was detected by automated molybdate colorimetry. Digested solutions were analyzed colorimetrically using 
Spectronic 21D Visible wavelength range spectrophotometer (Milton Roy Company, Rochester, NY, USA)

A novel multi-element scanning thermal analysis (MESTA) technique (Hsieh, 2007) was used to determine the total carbon, nitrogen, and hydrogen content, and to generate $\mathrm{C}$ and $\mathrm{N}$ thermograms of the biochar. A solid sample was inserted into the quartz combustion chamber and heated from ambient temperature to $750^{\circ} \mathrm{C}$ at a rate of $50^{\circ} \mathrm{C} /$ minute. $\mathrm{A} 33 \%$ oxygen in helium carrier gas is flushed through the sample chamber throughout the analysis. The sample is oxidized and the respective gases $\left(\mathrm{CO}_{2}, \mathrm{NO}_{2}\right.$, and $\mathrm{H}_{2} \mathrm{O}$ vapor) are quantified and recorded over the combustion range. A Cystine standard was used to calibrate the temperature range in each run. Arginine-KHP standards of known concentration were used to generate a calibration curve in order to determine the concentration of $\mathrm{C}$ and $\mathrm{N}$ in the analyzed samples. Due to the high concentration of carbon in the biochar samples, a $1 / 5$ dilution of biochar in baked talc $\left(900^{\circ} \mathrm{C}\right.$ for 30 minutes) was required to obtain a representative thermogram for the thermochemical analysis. Losses of $\mathrm{C}, \mathrm{N}$, and $\mathrm{H}$ from the conversion of switchgrass to biochar were calculated from a theoretical mass balance equation based on the yield of biochar. Carbon and $\mathrm{N}$ recovered at $<400{ }^{\circ} \mathrm{C}$ and $>400{ }^{\circ} \mathrm{C}$ were considered low thermal stability and high thermal stability C, respectively.

\section{Phosphorus sorption}

Two grams of sample ( $10 \%$ biochar and $90 \%$ sandy soil) was placed in $50-\mathrm{mL}$ centrifuge tubes and treated with $10 \mathrm{~mL}$ of solution containing $30 \mathrm{mg} \mathrm{P} \mathrm{L}^{-1}$. Ten percent biochar was used in this study following Xu et al., (2014) observation, after using 1-10\% biochar there was a significant response on $\mathrm{P}$ sorption and $\mathrm{pH}$ relationship. Thereafter, the tubes were shaken for a $24-\mathrm{h}$ 
equilibration using an end-over- end mechanical shaker at $25 \pm 2^{\circ} \mathrm{C}$. The equilibrated samples were centrifuged at $2500 \mathrm{rpm}$ for $15 \mathrm{~min}$ and filtered through a $0.45-\mathrm{mm}$ membrane filter. The filtrate was acidified with a drop of concentrated $\mathrm{H}_{2} \mathrm{SO}_{4}$ and stored at $4{ }^{\circ} \mathrm{C}$. Soluble reactive $\mathrm{P}$ was detected by automated molybdate colorimetry. Digested solutions were analyzed colorimetrically using Spectronic 21D Visible wavelength range spectrophotometer (Milton Roy Company, Rochester, NY, USA) Phosphorus not recovered in solutions was considered as the amount adsorbed by the biochar and soil mixture. Phosphorus sorption/desorption as influenced by biochar amendment was calculated as the percent of the difference between $\mathrm{P}$ sorbed by sandy soil amended with biochar and $\mathrm{P}$ sorbed by sandy soil not amended with biochar. Negative sorption values indicate $\mathrm{P}$ desorption.

\section{${ }^{13}$ C Solid state Nuclear Magnetic Resonance (ssNMR)}

Samples of ground biochar produced at different temperatures were analyzed by magic angle spinning (MAS) ${ }^{13} \mathrm{C}$ ssNMR. MAS ${ }^{13} \mathrm{C}$ ssNMR experiments were carried out on a Bruker $300 \mathrm{MHz}$ DRX NMR spectrometer equipped with a Bruker $4.0 \mathrm{~mm}$ double-resonance MAS NMR probe. Samples were packed into $4.0 \mathrm{~mm}$ zirconia rotors with Kel-F drive caps and spun to $9.5 \mathrm{kHz}$ at RT using a Bruker pneumatic MAS unit. All ${ }^{13} \mathrm{C}$ signals were enhanced by Cross Polarization: A $4.0 \mu \mathrm{s} 1 \mathrm{H} \pi / 2$ pulse followed by a $1 \mathrm{H}$ spin-lock field of $45 \mathrm{kHz}$ for $1.5 \mathrm{~ms}$ contact time, during which the ${ }^{13} \mathrm{C}$ RF field was ramped from 35 to 50 kHz. All ${ }^{13} \mathrm{C}$ signals were then recorded under the irradiation of the SPINAL64 decoupling sequence [ref J. Magn. Reson. 142 (2000)97-101] with 1H RF amplitude of $62.5 \mathrm{kHz}$. The number of scans used to accumulate the signals was varied between 10,000 to 50,000 , depending on the samples, with a recycle delay of $3 \mathrm{~s}$. The MAS ${ }^{13} \mathrm{C}$ ssNMR spectral regions were integrated to determine the contribution of each C functional group in the sample based on assignments from Knicker (2011): alkyl (0-45 ppm), methoxyl (45-60 ppm), O-alkyl (60-110 ppm), aromatic (110-140 ppm), phenolic (140-160 ppm), and carboxyl 
(160-220 ppm). The percent $\mathrm{C}$ of functional group was converted to $\mathrm{g}$ functional group $\mathrm{C} \mathrm{kg}^{-1}$ sample using TC values of the biochar samples.

\section{RESULTS}

\section{Feedstock and biochar physical and biogeochemical parameters}

The composition of metals in the three feedstocks indicated higher concentration of $\mathrm{K}$ $(P<0.0001), \mathrm{Ca}(P<0.0001), \mathrm{Mg}(P<0.0001)$, Fe $(P=0.0011)$ and $\mathrm{Al}(P=0.0475)$ in kudzu compared to switchgrass and Chinese tallow. The Fe and Al concentrations were noticeably low in all the three feedstocks, while Ca was more than three times higher in kudzu compared to switch grass and Chinese tallow (Table 1)

Biochar recovery after the pyrolysis process decreased with increasing pyrolysis temperature ranging from $78.0 \pm 1.5 \%$ to $22.8 \pm 0.2 \%$ in switchgrass $(P<0.0001), 74.0 \pm 2.3 \%$ to $23.4 \pm 0.2 \%$ in kudzu $(P<0.0001)$ and $80.0 \pm 0.4 \%$ to $17.5 \pm 0.6 \%$ in Chinese tallow $(P<0.0001)$ (Table 2$)$. Chinese tallow exhibited the greatest percentage reduction in biochar recovery as pyrolysis temperature increased. But, biochar concentration increased with increasing pyrolysis temperature for all feedstocks ranging from $54-81 \%$ for switch grass, $53-68 \%$ for kudzu and 52 93\% for Chinese tallow (Table 3; Figure 1). Chinese tallow exhibited the highest C concentration increase and switchgrass had the lowest $\mathrm{C}$ concentration increase with increasing pyrolysis temperature. However, as a result of the dramatic decrease in biochar recovery with increasing pyrolysis temperature there was an increased C loss with increasing pyrolysis temperature (Table 3). The C loss from lowest to highest pyrolysis temperature ranged from 18 to 65\%, 25- 
$71 \%, 14-69 \%$ in switchgrass, kudzu and Chinese tallow, respectively. However, changes in $\mathrm{N}$ concentration and loss were not consistent with the changing pyrolysis temperature (Table 3).

Biochar $\mathrm{pH}$ changed from neutral to alkaline with increasing pyrolysis temperature for all feedstocks, ranging from 7.1-11.3, 7.8-12.4 and 7.0-11.2 for switchgrass, kudzu and Chinese tallow, respectively (Table 2). The increasing biochar $\mathrm{pH}$ with increasing pyrolysis temperature was consistent with the high Ca and low Fe and Al concentration in all feedstocks (Table 1).

\section{Carbon thermograms}

Carbon thermograms indicated that, for biochar produced at 200 and $300^{\circ} \mathrm{C}$ the major $\mathrm{C}$ peak was at $<400^{\circ} \mathrm{C}$ (low thermal stable $\mathrm{C}$ area) of the thermograms but the peak shifted to $>400^{\circ} \mathrm{C}$ (high thermal stable $\mathrm{C}$ area) when biochar was produced at more than $300^{\circ} \mathrm{C}$ (Figure 1 ). The low thermal stable $\mathrm{C}$ and $\mathrm{N}\left(<400^{\circ} \mathrm{C}\right)$ decreased with increasing biochar pyrolysis temperature while the high thermal stable $\mathrm{C}$ increased with increasing biochar pyrolysis temperature (Figure

\section{2). Solid State ${ }^{13}$ C Nuclear Magnetic Resonance (NMR)}

While, carbon thermograms indicated that the biochar $\mathrm{C}$ shifted from low thermal stable $\mathrm{C}$ to high thermal stable carbon with increasing pyrolysis temperature. The ${ }^{13} \mathrm{C}$ NMR further indicated the specific $C$ functional groups response to increased pyrolysis temperature (Figure 3; Table 4). It was evident that there was a shift from less stable to more stable $\mathrm{C}$, whereby, for the raw materials (before pyrolysis process) $\mathrm{C}$ was dominantly in form of less stable $\mathrm{O}$-alkyl $\mathrm{C}$ being $42 \%, 35 \%$ and $41 \%$ in switchgrass, kudzu and Chinese tallow, respectively but at $300^{\circ} \mathrm{C}$ pyrolysis temperature carbon forms were dominated by aromatic and alkyl C at $20 \%$ and $18 \%$, $18 \%$ and $24 \%, 23 \%$ and $15 \%$ for switchgrass, kudzu and Chinese tallow, respectively. When the 
pyrolysis temperature was raised to 500 and $750{ }^{\circ} \mathrm{C}$ aromatic $\mathrm{C}$ was the dominant form of $\mathrm{C}$ (Figure 3; Table 4). O-alkyl C decrease with increasing pyrolysis temperature and negatively correlated with phenolic $(P=0.0038 ; r=-0.76)$, alkyl $(P=0.0329 ; r=-0.62)$ and aromatic $C(P=$ 0.002; $r=-0.79)$. In addition, phenolic and aromatic $C$ correlated positively $(P=0.0497 ; r=0.6)$ (Figure 4).

\section{Phosphorus sorption}

Results on P sorption of a mixture of $10 \%$ biochar and $90 \%$ sandy soils indicated that generally, P sorption increased with increasing pyrolysis temperature (Figure 4). Kudzu exhibited the highest $\mathrm{P}$ sorption compared with switchgrass and Chinese tallow at the same temperature. More specifically, kudzu maximum $\mathrm{P}$ sorption occurred at two biochar pyrolysis temperatures which included $400^{\circ} \mathrm{C}$ and $750^{\circ} \mathrm{C}$. However, both switchgrass and Chinese tallow maximum $\mathrm{P}$ sorption occurred only at $750^{\circ} \mathrm{C}$. All feedstock exhibited $\mathrm{P}$ desorption when biochar was produced at $200{ }^{\circ} \mathrm{C}$, however switchgrass is the only feedstock that exhibited P desorption when biochar was produced at between $300-550^{\circ} \mathrm{C}$ pyrolysis temperatures (Figure 5). The results for biochar available $\mathrm{P}$ contrasted the $\mathrm{P}$ sorption pattern, whereby, biochar available $\mathrm{P}$ decreased with increasing pyrolysis temperature (Figure 5). The lowest biochar available P was observed at $750{ }^{\circ} \mathrm{C}$ pyrolysis temperature for all feedstocks. However, the pyrolysis temperature that produced the highest biochar available $P$ varied from one feedstock to another whereby, highest biochar available $\mathrm{P}$ was observed at 300 and $500^{\circ} \mathrm{C}$ for switchgrass, $200^{\circ} \mathrm{C}$ for kudzu and $300^{\circ} \mathrm{C}$ for Chinese tallow (Figure 5). Phosphorus sorption correlated 
negatively with $\mathrm{P}$ availability $(P<0.0001 ; r=-0.63)$ and specifically for switchgrass $(P<0.0001 ; r=$ -0.83), kudzu $(P<0.0001 ; r=-0.99)$ and Chinese tallow $(P<0.0001 ; r=-0.89)$ (Figure 6).

Phosphorus sorption correlated positively with increasing high thermal stable $\mathrm{C}$ for switchgrass $(P=0.2186 ; r=0.53)$, kudzu $(P=0.0346 ; r=0.79)$ and Chinese tallow $(P=0.0138 ; r=0.86)$, while $P$ sorption correlated negatively with low thermal stable C (Figure 7). In addition, P sorption generally correlated positively with the $\mathrm{pH}(P<0.0001 ; \mathrm{r}=0.7)$ and more specifically with switchgrass $(P=0.001 ; r=0.66)$, kudzu $(P<0.0001 ; r=0.84)$ and Chinese tallow $(P<0.0001 ; r=$ 0.88) (Figure 8).

\section{DISCUSSION}

The study indicated that elevation of biochar pyrolysis temperature was consistent with increased $\mathrm{P}$ sorption and decreased $\mathrm{P}$ availability. However, the optimum $\mathrm{P}$ sorption was feedstock specific, with kudzu registering maximum $\mathrm{P}$ sorption at 400 and $700^{\circ} \mathrm{C}$ pyrolysis temperature while switchgrass and Chinese tallow registered the same at $700^{\circ} \mathrm{C}$. It is notable that in many cases biochar for agronomic application is often produced at $300-500{ }^{\circ} \mathrm{C}$ (Hale et al., 2013; Xu et al., 2014; Zhai et al., 2015), these temperatures in some cases could be out of the biochar pyrolysis range that optimize P sorption. In addition, P desorption was observed for all feedstocks when biochar was produced at $200{ }^{\circ} \mathrm{C}$ and for switchgrass between $200-550^{\circ} \mathrm{C}$. This indicates a possibility for $\mathrm{P}$ mineralization from biochars into the soil solution during incubation (Chintala et al., 2014). It also implies that it is not viable to produce switchgrass biochar at this temperature range when addressing $\mathrm{P}$ sorption. This suggest that care should be taken when selecting the optimum pyrolysis temperature for a specific feedstock for 
optimization of $\mathrm{P}$ sorption. This elucidates the contrasting observations on $\mathrm{P}$ sorption responses when biochar was produced at different temperatures using different feedstocks (Uzoma et al., 2011, Madiba et al., 2016). Therefore conclusion on the viable use of biochar for P sorption cannot be made without clear understanding of the biochar optimum pyrolysis temperature needed for this purpose.

Generally, elevated biochar pyrolysis temperature favored P sorption and reduced P availability. It was clear that increased biochar pyrolysis temperature transformed C from low thermal stable carbon dominated by O-alkyl C which is considered highly labile C (Mahieu et al., 1999; Spielvogel et al., 2008) to high thermal stable $C$ dominated by aromatic $C$ which is considered chemically stable C (Haumaier and Zech, 1995). The increase of aromatic C with increasing biochar pyrolysis temperature was in agreement with (McBeath et al., 2014) earlier observation. The $\mathrm{C}$ transformation with increasing pyrolysis temperature in our study was consistent with increased biochar $\mathrm{P}$ sorption and decrease in $\mathrm{P}$ availability, indicating increased sorption sites for P (lyamuremye et al., 1996). These findings were consistent with the study by (Keiluweit et al., 2009) that volatile components of both wood and grass char decrease substantially with increasing pyrolysis temperature while fixed $C$ and surface area value indicated a reverse trend. Phosphorus sorption by biochars may occur mainly due to the exchange between anions of $\mathrm{P}$ in solution with the oxygenated functional groups on surface of biochars which could be provided by volatile organic compound (Chintala et al., 2014).

Our results indicated that there was decreased biochar recovery, increased high thermal stable $\mathrm{C}$ and increasing $\mathrm{C}$ loss with increasing pyrolysis temperature. In addition, $\mathrm{P}$ sorption is maximized at higher compared to lower pyrolysis temperatures. This raises the question 
whether it is environmentally sustainable and viable to lose the huge quantity of $C$ in the process of biochar production for enhancement of $\mathrm{P}$ sorption in the face of climate change (Woolf, 2010). However, anaerobic bioenergy production mainly utilizes high pyrolysis temperatures, and addition of biochar in soils combined with bioenergy production has been suggested as a means to mitigate climate change (Lehmann, 2007a; Lehmann, 2007b).

Generally, there was a positive relation between increasing biochar alkalinity and $\mathrm{P}$ sorption and a negative relationship between alkaline $\mathrm{pH}$ and $\mathrm{P}$ availability. These findings are consistent with Harrell and Wang, (2006) that sorption of $P$ and its availability is influenced by soil solution $\mathrm{pH}$, metal oxides, and carbonates. The observed relationships between biochar alkaline $\mathrm{pH}, \mathrm{P}$ sorption and availability were enhanced by the high concentration of $\mathrm{Ca}$ and $\mathrm{Mg}$ in the feedstocks resulting in the formation of metal complexes such as Ca-P and Mg-P (Amer et al., 1985; Marschner, 1995). In our study, kudzu evidently contained threefold Ca content compared to other feedstocks, and as a result demonstrated the greatest $\mathrm{P}$ sorption. Our findings contrasted (Chintala et al., 2014) observation that application of alkaline biochar on acidic soils promoted $\mathrm{P}$ desorption and $\mathrm{P}$ availability which was attributed to point of zero charge and an increase in negative surface charge potential.

In conclusion, Biochar has potential for $\mathrm{P}$ eutrophication mitigation if produced at the optimum pyrolysis temperature. High biochar pyrolysis temperature favored accumulation of thermally stable $\mathrm{C}$ dominated by aromatic $\mathrm{C}$ as well as promoted increased alkalinity due to high concentration of $\mathrm{Ca}$ and $\mathrm{Mg}$ promoting $\mathrm{P}$ sorption and suppressing $\mathrm{P}$ availability. However, when optimizing biochar P sorption, optimal biochar pyrolysis temperature is feedstock specific and care should be taken when choosing the pyrolysis temperature to ensure optimization of $P$ 
sorption for eutrophication mitigation. Further research is required to separate the influence of carbon stability and $\mathrm{pH}$ on $\mathrm{P}$ sorption. Field research is needed to verify these effects of biochars on the transformations of $P$ in soil.

\section{ACKNOWLEDGEMENT}

Special thanks to Dr. Oghenekome Onokpise for helping with plant species identification, Dr. Amita Jain for metal analysis and Dr. Glynnis Bugna for helping with laboratory analysis. A portion of this work was performed at the National High Magnetic Field Laboratory, which is supported by National Science Foundation Cooperative Agreement No. DMR-1157490 and the State of Florida. In addition, was supported by USDA-Forest Service Southern Research Station award number 16-CA-11330140-046

\section{REFERENCES}

Amer, F.A., Mahmound, A.A., Sabet, V., 1985. Zeta-Potential and surface area of calcium carbonate as related to phosphate sorption. Soil sci. Soc. AM. J. 49, 1137-1142.

Bergström, L., Kirchmann, H., Djodjic, F., Kyllmar, K., Ulén, B., Liu J., Andersson, H., Aronsson, H., Börjesson, G., Kynkäänniemi, P., Svanbäck, A., Villa, A., 2015. Turnover and Losses of Phosphorus in Swedish Agricultural Soils:Long-Term Changes, Leaching Trends, and Mitigation Measures. J. Environ. Qual. 44, 512-523. 
Cabera, A., Cox, L., Spokas, K., Hermosin, M.C., Cornejo, J., Koskinen, W.C., 2011. Comparative Sorption and Leaching Study of the Herbicides Fluometuron and 4-Chloro-2methlylphenoxyacetic Acid (MCPA) in a Soil Amended with Biochars and Other Sorbents. J. Agric. Food Chem. 59, 12550-12560.

Cao, X., Ma, L., Gao, L.B., Harris, W., 2009. Dairy-Manure Derived Biochar Effectively Sorbs Lead and Atrazine, Environ. Sci. Technol. 43, 3285-3291.

Carpenter, S.R., 2008. Phosphorus control is critical to mitigating eutrophication. PNA 105 (32), 11039-11040.

Chen, B., Chen Z., 2009. Sorption of naphthalene and 1-naphthol by biochars of orange peels with different pyrolytic temperatures. Chemosphere 76, 127-133.

Chen, Y., Shinogi, Y. Taira, M., 2010. Influence of biochar use on sugarcane growth, soil parameters, and groundwater quality. Aust. J. Soil Res. 48 (7), 526-530

Chintala, R., Mollinedo, J., Schumacher, T.E., Malo, D.D., Papiernik, S.K., Clay, D.E., Kumar, S., Gulbrandson, D.W., 2013. Nitrate Sorption and Desorption in Biochars from Fast Pyrolysis. Micropor. Mesopor. Mat. 179,250-257.

Chintala, R., Schumacher, T.E., McDonald, L.M., Clay, D.E., Malo, D.D., Papiernik, S.K., Clay, S.A. Julson, J.L., 2014. Phosphorus Sorption and Availability from Biochars and Soil/Biochar Mixtures. Clean - Soil Air Water, 42 (5), 626-634.

Dari, B., Nair, V. D., Colee, J., Harris, W. G., Mylavarapu, R., 2015. Estimation of phosphorus isotherm parameters: a simple and cost-effective procedure. Front. Environ. Sci., 3, 70. 
Dari, B., Nair, V. D., Harris, W. G., Nair, P. K. R., Sollenberger, L. Mylavarapu, R., 2016. Relative influence of soil-vs. biochar properties on soil phosphorus retention. Geoderma, 280, 82-87.

DeLuca, T.H., MacKenzie, D., Gundale, M., 2009. Biochar Effects on Soil Nutrient Transformations. In: Lehmann, J., Joseph, S. (Eds.), Biochar for Environmental Management: Science and Technology. Earthscan, London, pp. 251-270.

Debicka, M., Kocowicz, A., Weber, J. Jamroz, E., 2016. Organic matter effects on phosphorus sorption in sandy soils. Arch. of Agron. Soil Sci. DOI: 10.1080/03650340.2015.1083981

Gaskin, J.W., Steiner, C., Harris, K., Das, K.C., Bibens, B., 2008. Effect of low-temperature pyrolysis conditions on biochar for agricultural use. American Society of Agricultural and Biological Engineers 51 (6), 2061-2069.

Glaser, B., Wiedner, K., Seelig, S., Schmidt, H.P., Gerber H., 2015. Biochar organic fertilizers from natural resources as substitute for mineral fertilizers. Agron. Sustain. Dev., 35, 667-678.

Hale, S.E., Alling, V., Martinsen, V., Mulder, J., Breedveld, G.D., Cornelissen, G., 2013. The sorption and desorption of phosphate- $\mathrm{P}$, ammonium- $\mathrm{N}$ and nitrate- $\mathrm{N}$ in cacao shell and corn cob biochars. Chemosphere 91, 1612-1619.

Haumaier, L. and Zech, W., 1995. Black carbon, possible source of highly aromatic components of soil humic acids. Org. Geochem. 23 (3), 191-196.

Harrell, D.L. Wang, J.J., 2006. Fractionation and Sorption of Inorganic Phosphorus in Louisiana Calcareous Soils, Soil Sci. 171, 39-51.

Self-Davis, M.L. Moore, Jr P.A., 2000. Determining Water Soluble Phosphorus in Animal Manure. P. 74-76. In G.M. Pierzynski (Ed.) Methods of Phosphorus Analysis for Soils, Sediments, 
Residuals and Waters. Southern Cooperative Series Bulletin \#396, North Carolina State Univ., Raleigh, NC.

Iyamuremye, F., Dick, R.P., Baham, J., 1996. Organic amendments and phosphorus dynamics: III. Phosphorus speciation. Soil Sci. 161, 444-451.

Kleinman, P.J.A., Sharpley, A.N., Withers, P.J.A., Bergstrom, L., Johnson, L.T., Doody, D.G., 2015. Implementing agricultural phosphorus science and management to combat eutrophication. Ambio, 44, 297-S310.

Kloss, S., Zehetner, F., Dellantonio, A., Hamid, R., Ottner, F., Liedtke, V., Schwanninger, M., Gerzabek, M.H., Soja, G., 2012. Characterization of slow pyrolysis biochars: effects of feedstocks and pyrolysis temperature on biochar properties, J. Environ. Qual. 41, 990-1000.

Keiluweit, M., Nico, P.S., Johnson, M.G., Kleber, M., 2009. Dynamic Molecular Structure of Plant Biomass-Derived Black Carbon (Biochar). Environ. Sci. Technol. 44, 1247-1253.

Knicker, H., 2011. Solid state CPMAS 13C and 15N NMR spectroscopy in organic geochemistry and how spin dynamics can either aggravate or improve spectra interpretation. Org. Geochem., 42(8), 867-890.

Lambers, H., Raven, J.A., Shaver, G.R. Smith, S.E., 2008. Plant nutrient-acquisition strategies change with soil age. Trends Ecol. Evol. , 23 (2).

Lehmann, J., 2007a. Bio-energy in the black. Frontiers in Ecology and the Environment 5:381387.

Lehmann, J. A., 2007b. Handful of carbon. Nature, 447 (7141), 143-144. 
Lehmann, J., Gaunt, J., Rondon, M., 2006. Bio-Char Sequestration in Terrestrial Ecosystems - a Review. Mitigation Adapt. Strategies Global Change 11, 403-427.

Leip, A., Billen, G., Garnier, J., Grizzetti, B., Lassaletta, L., Reis, S., Simpson, D., Sutton, M.A., de Vries, W., Weiss, F., 2015.Impacts of European livestock production: nitrogen, sulphur, phosphorus and greenhouse gas emissions, land-use, water eutrophication and biodiversity. Environ Res Lett. 10: 115004. doi:10.1088/1748-9326/10/11/115004.

Lindsay, W.L., 1979. Chemical Equilibria in Soils, John Wiley \& Sons, New York.

Marschner, H., 1995. Mineral nutrition of higher plants, Academic press, London.

Nelson, N.O., Sandra, A., Wenqiao, Y. Jing, G., 2011. Nitrogen and Phosphorus Availability in Biochar-Amended Soils. Soil Sci. 176 (5), 218-226.

Park, J.H., Ok, Y.S., Kim, S.H., Cho, J.S., Heo, J.S., Delaune, R.D. Seo, D.C., 2015. Evaluation of phosphorus adsorption capacity of sesame straw biochar on aqueous solution: influence of activation methods and pyrolysis temperatures. Environ. Geochem. Health, 37,969-983.

Madiba, O.F., Solaiman, Z.M., Carson, J.K., Murphy, D.V., 2016. Biochar increases availability and uptake of phosphorus to wheat under leaching conditions. Biol. Fertil. Soils 52,439-446.

Mahieu, N., Powlson, D.S., Randall, E.W., 1999. Statistical analysis of published carbon-13

CPMAS NMR spectra of soil organic matter. Soil Science Society of America Journal, 63, 307319. 
McBeath, A.V., Smernik, R.J., Krull, E.S. Lehmann, J. 2014. The influence of feedstock and production temperature on biochar carbon chemistry: A solid-state $13 C$ NMR study. Biomass Bioenerg. 60,121-129.

Marschner, H., 1995. Mineral Nutrition of Higher Plants, Academic Press, London.

Meinikmann, K., Hupfer, M., Lewandowski, J., 2015. Phosphorus in groundwater discharge -A potential source for lake eutrophication. J. Hydrol. 524,214-226.

McDowell, R.W., Cox, N., Daughney, C.J., Wheeler, D. Moreau, M., 2015. A national assessment of the potential linkage between soil, and surface and groundwater concentrations of phosphorus. J. Am. Water Resour. As. 51 (4)

Mukherjee, A., Zimmerman, A.R., Harris, W., 2011. Surface chemistry variations among a series of laboratory-produced biochars. Geoderma 163, 247-255.

Rajkovich, S., Enders, A., Hanley, K., Hyland, C., Zimmerman, A.R., Lehmann, J., 2012. Corn growth and nitrogen nutrition after additions of biochars with varying properties to a temperate soil. Biol. Fertil. Soils 48, 271-284.

Sage, R.F., Coiner, H.A., Way, D.A., Runion, G.B., Prior, S.A., Torbert, H.A., Sicher, R., Ziska L., 2009. Kudzu [Pueraria montana (Lour.) Merr. Variety lobata]: A new source of carbohydrate for bioethanol production. Biomass Bioenerg.33 (1), 57-61.

Sample, E.C.R., Soper, R.J., Racz, G.J., 1980. Reaction of phosphate fertilizers in soils, in The Role of Phosphorus in Agriculture (Ed.: R.C. Dinauer), American Society of America, Madison, WI 1980, pp. 263-304. 
Schindler, D.W., Carpenter, S.R., Chapra, S.C. Hecky, R.E., Orihel, D.M., 2016. Reducing phosphorus to curb lake eutrophication is a success. Environ. Sci. Technol. DOI: 10.1021/acs.est.6b02204.

Siddique, M.T., Robinson, J.S., 2004. Differences in phosphorus retention and release in soils amended with animal manures and sewage sludge. Soil Sci. Soc. Am. 68 (4):1421-1428.

Sharpley, A., Foy, B., Withers, P., 2000. Practical and innovative measures for the control of agricultural phosphorus losses to water: An overview. J. Environ. Qual. 29(1).

Sharpley, A.N., Bergstro“m, L., Aronsson, H., Bechmann, M., Bolster, C.H., Bo“rling, K., Djodjic, F., Jarvie, H.P., Schoumans, O.F., Stamm, C., Tonderski, K.S., Ule'n, B., Uusitalo, R. Withers, P.J.A., 2015. Future agriculture with minimized phosphorus losses to waters: Research needs and direction. Ambio, 44 (Suppl. 2), S163-S179.

Spielvogel, S., Prietzel, J., Kogel-Knabner, I., 2008. Soil organic matter stabilization in acidic forest soils is preferential and soil type-specific. Eur. J. Soil Sci. 59,674-692.

Ulrich, A.E., Malley, D.F., Watts, P.D., 2016. Lake Winnipeg Basin: Advocacy, challenges and progress for sustainable phosphorus and eutrophication control. Sci. Total Environ. 542, 10301039.

Uzoma, K.C., Inoue, M., Andry, H., Zahoor, A., Nishihara, E., 2011. Influence of biochar application on sandy soil hydraulic properties and nutrient retention. J. Food Agric. Environ. 9 (3\&4), 1137-1143. 
Villapando, R.R. and Graetz, D.A., 2001. Phosphorus Sorption and Desorption Properties of the Spodic Horizon from Selected Florida Spodosols. Soil Sci. Soc. Am. 65,331-339

Withers, P.J.A., Flynn, N.J., Warren, G.P., Taylor, M. Chambers, B.J., 2016. Sustainable management of biosolids phosphorus: a field study. Soil use Manage. 32 (Suppl. 1)54-63.

Woolf, D., Amonette, J.E., Street-Perrott, F.A., Lehmann, J. Joseph, S., 2010. Sustainable biochar to mitigate global climate change. Nature communication 1:56 DOI: 10.1038/ncomms1053.

Xu, G., Suna, J., Shaoa, H., Changa, S.X., 2014. Biochar had effects on phosphorus sorption and desorption in three soils with differing acidity. Ecol. Eng. 62, 54-60.

Yuch-Ping, H., 2007. A Novel Multielemental Scanning Thermal Analysis (MESTA) Method for the Identification and Characterization of Solid Substances. J. AOAC Int. 90 (1), 54-59(6).

Zhai, L., CaiJi, Z., Liu, J., 2015. Short-term effects of maize residue biochar on phosphorus availability in two soils with different phosphorus sorption capacities. Biol Fert Soils 51,113122.

Zhao, L., Cao, X., Masek, O., Zimmerman, A., 2013. Heterogeneity of biochar properties as a function of feedstock sources and production temperatures. J. Hazard Mater. 256- 257, 1-9.

Zheng, W., Guo, M., Chow, T., Bennett, D.N., Rajagopalan, N., 2010. Sorption Properties of Green Waste Biochar for Two Triazine Pesticides. J. Hazard. Mater. 181, 121-126. 


\section{TABLES}

Table 1. Feedstock metal concentration, Data indicate mean \pm SEM (standard error of mean) between metals. Different letters superscript along the column indicate Tukey HSD significant difference between means of potassium (K), calcium (Ca), magnesium (Mg), iron (Fe) and aluminum (Al) in switchgrass, kudzu and Chinese tallow.

\begin{tabular}{llllll}
\hline Feedstock & $\mathrm{K}$ & $\mathrm{Ca}$ & $\mathrm{Mg}$ & $\mathrm{Fe}$ & $\mathrm{Al}$ \\
& \multicolumn{5}{c}{$\mathrm{Mg} \mathrm{kg}^{-1}$} \\
\hline Switchgrass & $3390 \pm 111^{\mathrm{b}}$ & $2834 \pm 102^{\mathrm{b}}$ & $2271 \pm 77^{\mathrm{b}}$ & $32 \pm 3^{\mathrm{b}}$ & $46 \pm 6^{\mathrm{ab}}$ \\
Kudzu & $7937 \pm 172^{\mathrm{a}}$ & $11790 \pm 295^{\mathrm{a}}$ & $3078 \pm 90^{\mathrm{a}}$ & $48 \pm 5^{\mathrm{a}}$ & $59 \pm 12^{\mathrm{a}}$ \\
Chinese Tallow & $421 \pm 55^{\mathrm{c}}$ & $3204 \pm 338^{\mathrm{b}}$ & $421 \pm 43^{\mathrm{c}}$ & $13 \pm 2^{\mathrm{c}}$ & $24 \pm 3^{\mathrm{b}}$ \\
P value & $<0.0001$ & $<0.0001$ & $<0.0001$ & 0.0011 & 0.0475 \\
\hline
\end{tabular}


Table 2. Biochar recovery, $\mathrm{pH}$ and loss on ignition. Data indicate mean \pm SEM (standard error of mean) between temperatures. Different letters superscript along the row indicate Tukey HSD significant difference between means of biochar recovery, $\mathrm{pH}$ and loss on ignition (LOI) under different temperatures.

\begin{tabular}{|c|c|c|c|c|c|c|c|c|}
\hline Temperature & $200^{\circ} \mathrm{C}$ & $300{ }^{\circ} \mathrm{C}$ & $400^{\circ} \mathrm{C}$ & $500^{\circ} \mathrm{C}$ & $550^{\circ} \mathrm{C}$ & $650^{\circ} \mathrm{C}$ & $750^{\circ} \mathrm{C}$ & $\mathrm{P}$ value \\
\hline \multicolumn{9}{|l|}{$\underline{\text { Switchgrass }}$} \\
\hline $\mathrm{BC}$ recovery $(\%)$ & $78.0 \pm 1.5^{\mathrm{a}}$ & $46.2 \pm 1.1^{\mathrm{b}}$ & $31.7 \pm 1.3^{\mathrm{c}}$ & $35.4 \pm 2.0^{\mathrm{c}}$ & $24.9 \pm 0.3^{\mathrm{d}}$ & $24.1 \pm 0.2^{\mathrm{d}}$ & $22.8 \pm 0.2^{\mathrm{d}}$ & $<0.0001$ \\
\hline $\mathrm{pH}$ & $7.1 \pm 0.4^{\mathrm{b}}$ & $8.0 \pm 0.3^{\mathrm{b}}$ & $9.3 \pm 1.0^{\mathrm{ab}}$ & $9.0 \pm 0.7^{\mathrm{ab}}$ & $10.7 \pm 0.04^{\mathrm{a}}$ & $11.3 \pm 0.1^{\mathrm{a}}$ & $11.3 \pm 0.2^{\mathrm{a}}$ & 0.0001 \\
\hline LOI $(\%)$ & $92.3 \pm 1.1^{\mathrm{a}}$ & $90.9 \pm 0.7^{\mathrm{ab}}$ & $88.7 \pm 0.3^{\mathrm{bc}}$ & $86.6 \pm 0.7^{\mathrm{c}}$ & $91.0 \pm 0.4^{\mathrm{ab}}$ & $83.0 \pm 0.2^{\mathrm{d}}$ & $77.9 \pm 0.6^{\mathrm{e}}$ & $<0.0001$ \\
\hline \multicolumn{9}{|l|}{$\underline{\text { Kudzu }}$} \\
\hline $\mathrm{BC}$ recovery $(\%)$ & $74.0 \pm 2.3^{\mathrm{a}}$ & $38.8 \pm 0.2^{\mathrm{b}}$ & $29.8 \pm 2.0^{\mathrm{c}}$ & $26.0 \pm 1.1^{\mathrm{cd}}$ & $26.9 \pm 0.5^{\mathrm{cd}}$ & $24.6 \pm 0.1^{\mathrm{cd}}$ & $23.4 \pm 0.2^{\mathrm{d}}$ & $<0.0001$ \\
\hline $\mathrm{pH}$ & $7.8 \pm 0.03^{\mathrm{e}}$ & $9.5 \pm 0.1^{\mathrm{d}}$ & $10.5 \pm 0.03^{c}$ & $11.3 \pm 0.1^{\mathrm{b}}$ & $11.1 \pm 0.2 b$ & $12.0 \pm 0.03^{\mathrm{a}}$ & $12.4 \pm 0.01^{\mathrm{a}}$ & $<0.0001$ \\
\hline LOI $(\%)$ & $81.1 \pm 2.9^{c}$ & $72.9 \pm 0.2^{\mathrm{d}}$ & $84.3 \pm 0.3^{c}$ & $98.4 \pm 0.4^{\mathrm{a}}$ & $94.5 \pm 0.2^{\mathrm{ab}}$ & $93.4 \pm 0.2^{\mathrm{ab}}$ & $92.1 \pm 0.2^{b}$ & $<0.0001$ \\
\hline \multicolumn{9}{|l|}{$\underline{\text { Chinese Tallow }}$} \\
\hline $\mathrm{BC}$ recovery $(\%)$ & $80.0 \pm 0.4^{\mathrm{a}}$ & $36.5 \pm 2.6^{\mathrm{b}}$ & $23.7 \pm 0.3^{\mathrm{c}}$ & $22.2 \pm 0.3^{\mathrm{cd}}$ & $20.6 \pm 0.9^{\mathrm{cd}}$ & $20.8 \pm 0.8^{\mathrm{cd}}$ & $17.5 \pm 0.6^{\mathrm{d}}$ & $<0.0001$ \\
\hline $\mathrm{pH}$ & $7.0 \pm 0.03^{\mathrm{c}}$ & $7.0 \pm 0.9^{c}$ & $8.8 \pm 0.1^{\mathrm{b}}$ & $8.9 \pm 0.05^{\mathrm{b}}$ & $8.9 \pm 0.1^{b}$ & $10.2 \pm 0.1^{\mathrm{ab}}$ & $11.2 \pm 0.3^{\mathrm{a}}$ & $<0.0001$ \\
\hline LOI (\%) & $91.5 \pm 0.4^{\mathrm{a}}$ & $81.9 \pm 2.2^{\mathrm{b}}$ & $72.5 \pm 2.1^{\mathrm{c}}$ & $96.6 \pm 2.2^{\mathrm{a}}$ & $82.1 \pm 0.1^{\mathrm{b}}$ & $74.7 \pm 1.8^{\mathrm{bc}}$ & $90.5 \pm 0.3^{\mathrm{a}}$ & $<0.0001$ \\
\hline
\end{tabular}

Table 3. Biochar total carbon and nitrogen, carbon and nitrogen loss and atomic C:N ratio for switchgrass, kudzu and Chinese tallow under different temperature 


\begin{tabular}{|c|c|c|c|c|c|c|c|c|}
\hline Temperature $\left({ }^{\circ} \mathrm{C}\right)$ & 0 & 200 & 300 & 400 & 500 & 550 & 650 & 750 \\
\hline \multicolumn{9}{|l|}{ Switchgrass } \\
\hline C (\%) & 54.2 & 57.0 & 65.6 & 76.1 & 78.8 & 84.2 & 75.0 & 81.6 \\
\hline$N(\%)$ & 0.9 & 0.6 & 0.8 & 1.0 & 1.0 & 1.2 & 1.0 & 1.0 \\
\hline atomic C:N & 68.0 & 105.5 & 92.9 & 91.2 & 93.0 & 79.5 & 88.5 & 100.1 \\
\hline Carbon loss (\%) & - & 18.2 & 44.0 & 55.6 & 48.7 & 61.3 & 66.2 & 64.7 \\
\hline Nitrogen loss (\%) & - & 0.1 & 0.4 & 0.7 & 0.6 & 0.9 & 0.8 & 0.7 \\
\hline \multicolumn{9}{|l|}{ Kudzu } \\
\hline$\% \mathrm{C}$ & 53.2 & 53.6 & 62.0 & 62.1 & 64.9 & 63.6 & 71.8 & 68.6 \\
\hline$\% \mathrm{~N}$ & 1.9 & 2.2 & 2.4 & 1.9 & 1.7 & 1.6 & 1.3 & 1.2 \\
\hline atomic C:N & 31.9 & 28.6 & 30.2 & 38.7 & 45.0 & 47.7 & 64.0 & 67.4 \\
\hline Carbon loss (\%) & - & 25.5 & 54.7 & 65.1 & 68.3 & 67.8 & 65.9 & 71.3 \\
\hline Nitrogen loss (\%) & - & 0.6 & 1.5 & 1.3 & 1.2 & 1.1 & 1.0 & 0.9 \\
\hline \multicolumn{9}{|l|}{ Chinese tallow } \\
\hline$\% \mathrm{C}$ & 52.6 & 56.6 & 68.8 & 73.8 & 83.9 & 80.2 & 89.9 & 93.2 \\
\hline$\% \mathrm{~N}$ & 0.3 & 0.5 & 0.8 & 0.7 & 0.8 & 0.7 & 0.8 & 0.9 \\
\hline atomic C:N & 176.9 & 122.1 & 101.6 & 117.7 & 122.9 & 131.4 & 138.1 & 124.3 \\
\hline Carbon loss (\%) & - & 13.9 & 52.2 & 66.7 & 64.6 & 68.6 & 63.8 & 69.0 \\
\hline Nitrogen loss (\%) & - & 0.1 & 0.5 & 0.6 & 0.6 & 0.6 & 0.6 & 0.7 \\
\hline
\end{tabular}

Table 4 . Biochar carbon composition as determined by solid state ${ }^{13} \mathrm{C}$ NMR for switchgrass, kudzu and Chinese tallow at different temperature. 


\begin{tabular}{|c|c|c|c|c|c|c|c|}
\hline & Carbon & Carboxyl & Phenolic & Aromatic & O-alkyl & Methoxyl & Alkyl \\
\hline & $\%$ & Carbon fra & ns (\%) & & & & \\
\hline \multicolumn{8}{|c|}{ Switchgrass } \\
\hline $0{ }^{\circ} \mathrm{C}$ & 54.2 & 1.5 & 1.8 & 2.8 & 42.4 & 2.8 & 3.0 \\
\hline $300{ }^{\circ} \mathrm{C}$ & 65.6 & 4.5 & 7.6 & 19.7 & 10.5 & 5.4 & 17.8 \\
\hline $500{ }^{\circ} \mathrm{C}$ & 78.8 & 1.7 & 8.9 & 48.7 & 7.0 & 1.9 & 10.6 \\
\hline $750{ }^{\circ} \mathrm{C}$ & 81.6 & 0.0 & 18.9 & 36.3 & 2.3 & 9.9 & 14.2 \\
\hline \multicolumn{8}{|l|}{$\underline{\text { Kudzu }}$} \\
\hline $0{ }^{\circ} \mathrm{C}$ & 53.2 & 3.2 & 1.2 & 2.1 & 35.4 & 3.7 & 7.6 \\
\hline $300{ }^{\circ} \mathrm{C}$ & 62 & 4.7 & 7.3 & 17.8 & 5.3 & 3.3 & 23.6 \\
\hline $500{ }^{\circ} \mathrm{C}$ & 64.9 & 3.7 & 8.5 & 40.7 & 4.2 & 1.2 & 6.7 \\
\hline $750{ }^{\circ} \mathrm{C}$ & 68.6 & 4.2 & 5.8 & 39.9 & 11.9 & 1.7 & 5.2 \\
\hline \multicolumn{8}{|c|}{ Chinese Tallow } \\
\hline $0^{\circ} \mathrm{C}$ & 52.6 & 1.2 & 2.3 & 2.1 & 40.7 & 4.1 & 2.2 \\
\hline $300{ }^{\circ} \mathrm{C}$ & 68.8 & 6.0 & 12.3 & 23.1 & 7.4 & 4.6 & 15.4 \\
\hline $500{ }^{\circ} \mathrm{C}$ & 83.9 & 2.4 & 11.9 & 54.2 & 6.0 & 1.8 & 7.7 \\
\hline $750{ }^{\circ} \mathrm{C}$ & 93.2 & 7.7 & 7.1 & 55.6 & 10.7 & 0.5 & 11.7 \\
\hline
\end{tabular}




\section{FIGURES}

Fig. 1 Carbon thermograms for switch grass, kudzu and Chinese tallow for raw materials and biochar produced at different pyrolysis temperature and determined by (multi-element scanning thermal analysis) MESTA

Fig. 2 Biochar low $\left(<400^{\circ} \mathrm{C}\right)$ and high $\left(>400^{\circ} \mathrm{C}\right)$ thermal stable carbon and nitrogen for switch grass, kudzu and Chinese tallow produced at different pyrolysis temperature

Fig 3 Switch grass, kudzu and Chinese tallow feedstock and biochar carbon composition determined by solid state ${ }^{13} \mathrm{C}$ NMR. The biochar was produced at 300,500 and $750{ }^{\circ} \mathrm{C}$

Fig. 4 A. Relationship between biochar O-alkyl carbon with aromatic, alkyl and phenolic carbon. B. Relationship between biochar phenolic and aromatic carbon

Fig. 5 Biochar, A. Phosphorus sorption, the graph indicate the percent difference between biochar amended soil P sorption and sandy soil P sorption for switch grass, kudzu and Chinese tallow. The letters along the temperature range indicate Tukey HSD significant difference in phosphorus sorption between different temperatures for each feedstock. B. Phosphorus availability under different pyrolysis temperatures for switch grass, kudzu and Chinese tallow. Different letters along the temperature range indicate Tukey HSD significant difference in phosphorus availability between different temperatures for each feedstock.

Fig. 6 Relationship between phosphorus sorption and available phosphorus for switchgrass, kudzu, Chinese tallow and all feedstocks 
Fig. 7 Relationship between phosphorus sorption with low thermal stable carbon $\left(<400{ }^{\circ} \mathrm{C}\right)$ and high thermal stable carbon $\left(>400^{\circ} \mathrm{C}\right)$ for switchgrass, kudzu and Chinese tallow.

Fig. 8 Relationship between biochar phosphorus sorption and pH for all feedstocks, switchgrass, kudzu and Chinese tallow. 


\section{FIGURES}

Fig. 1

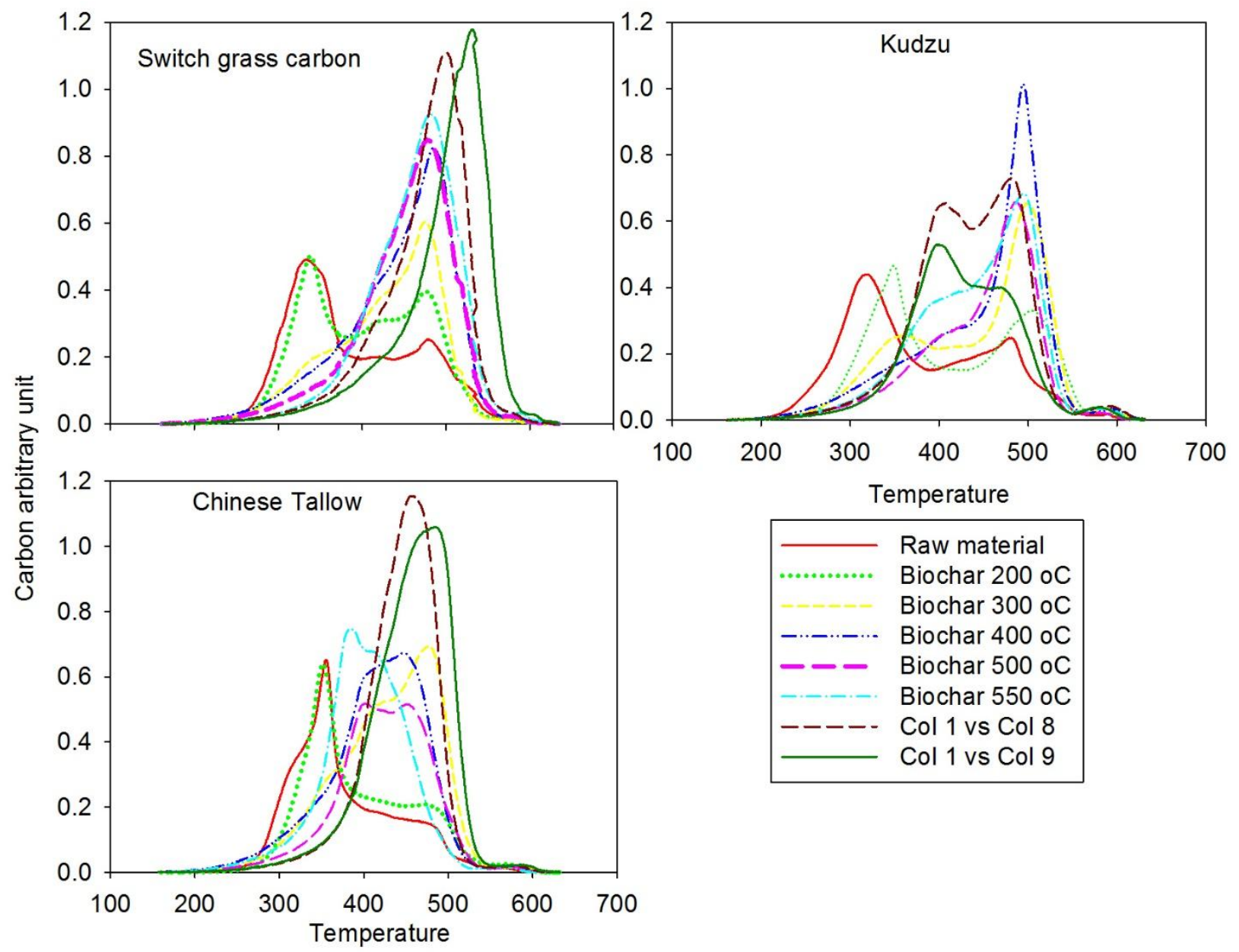


Fig. 2

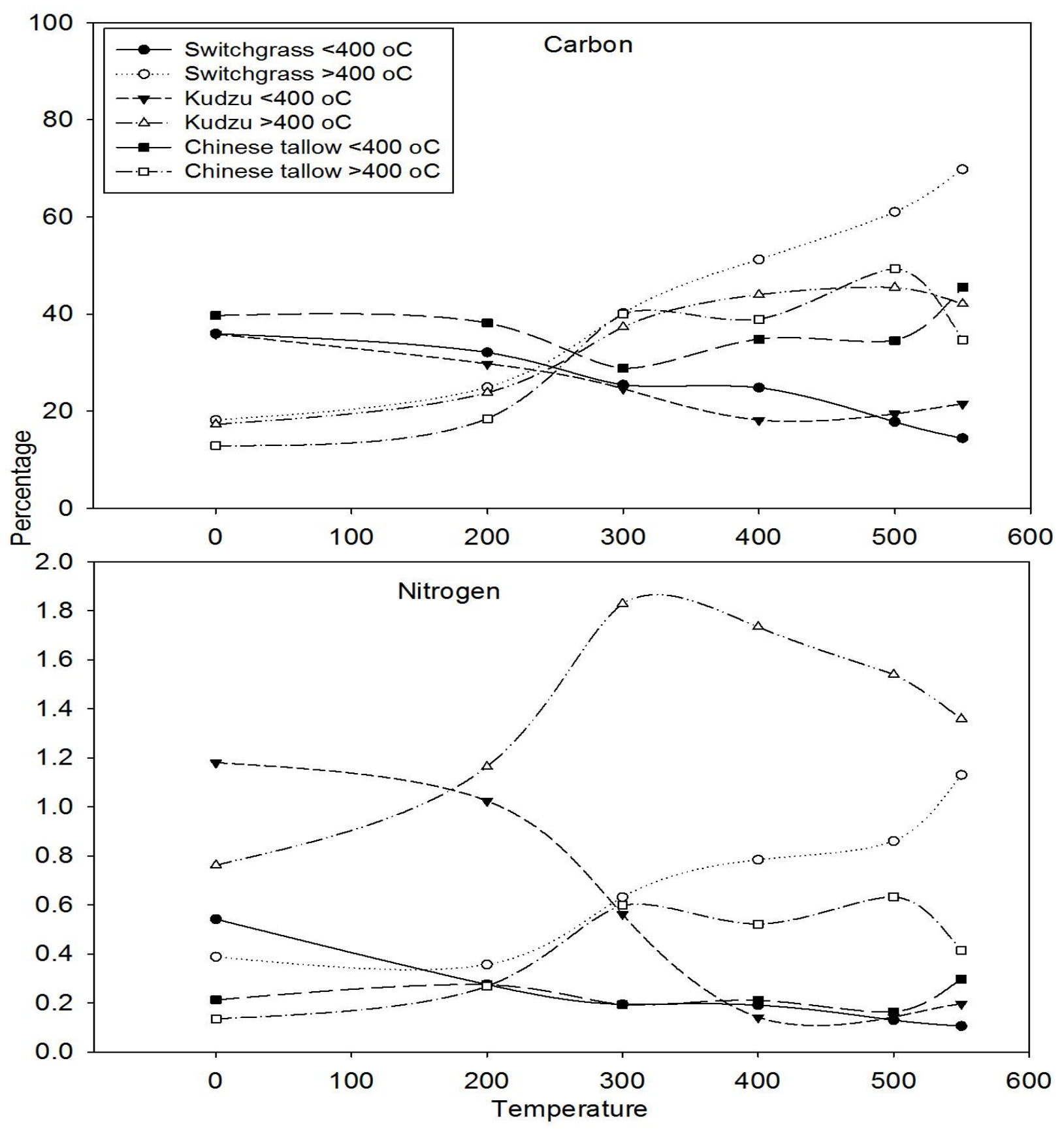


Fig 3

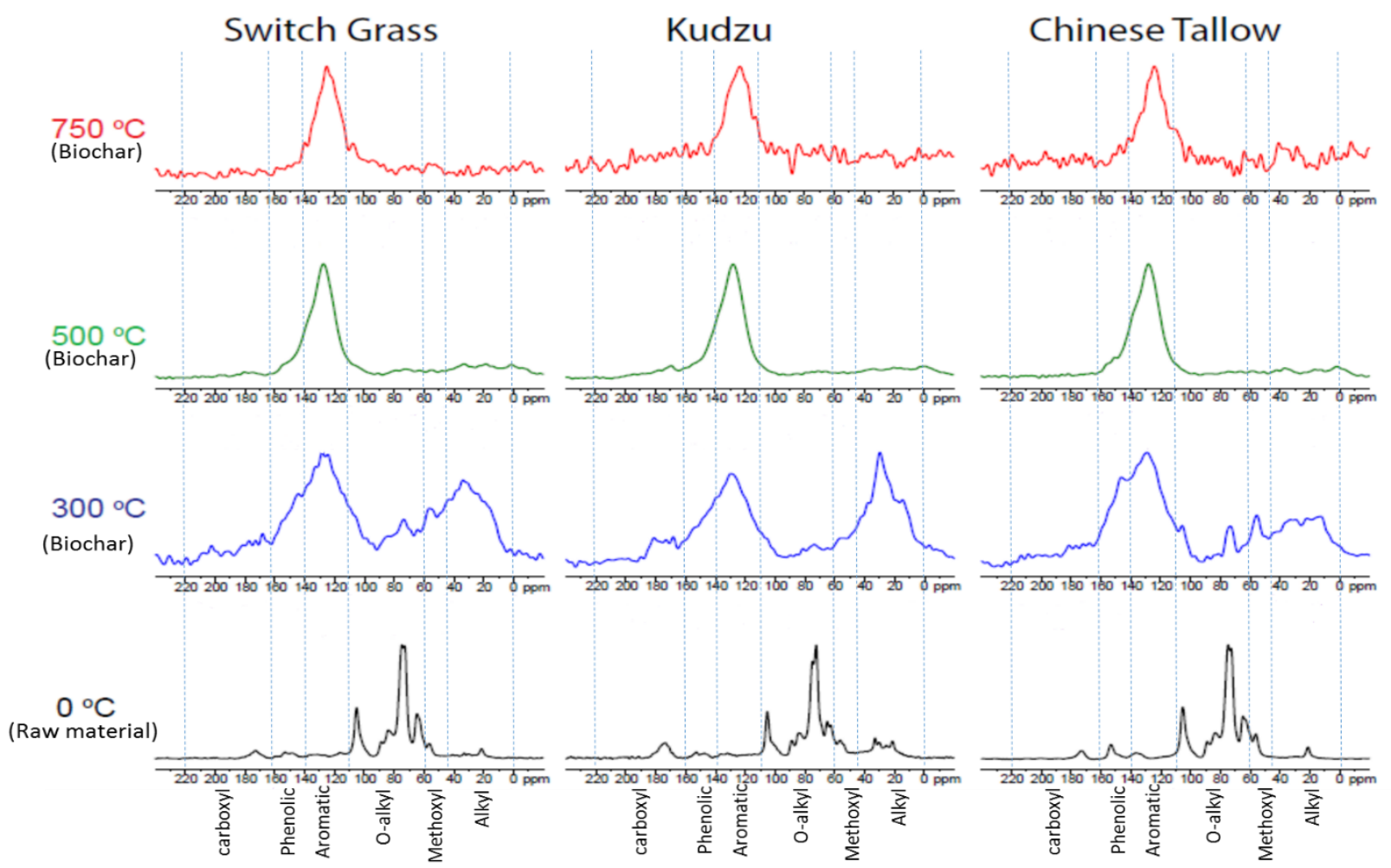


Fig. 4
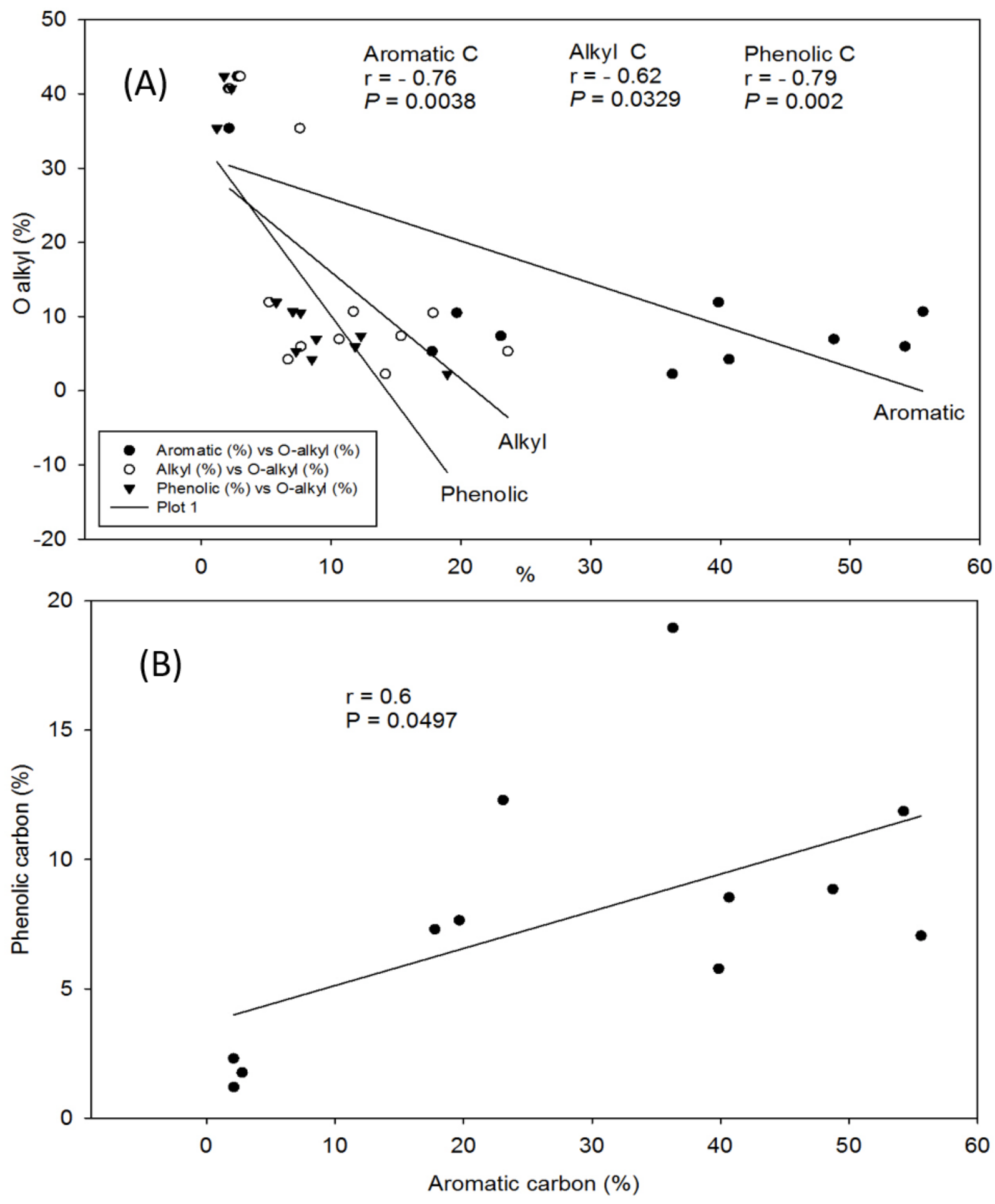
Fig. 5
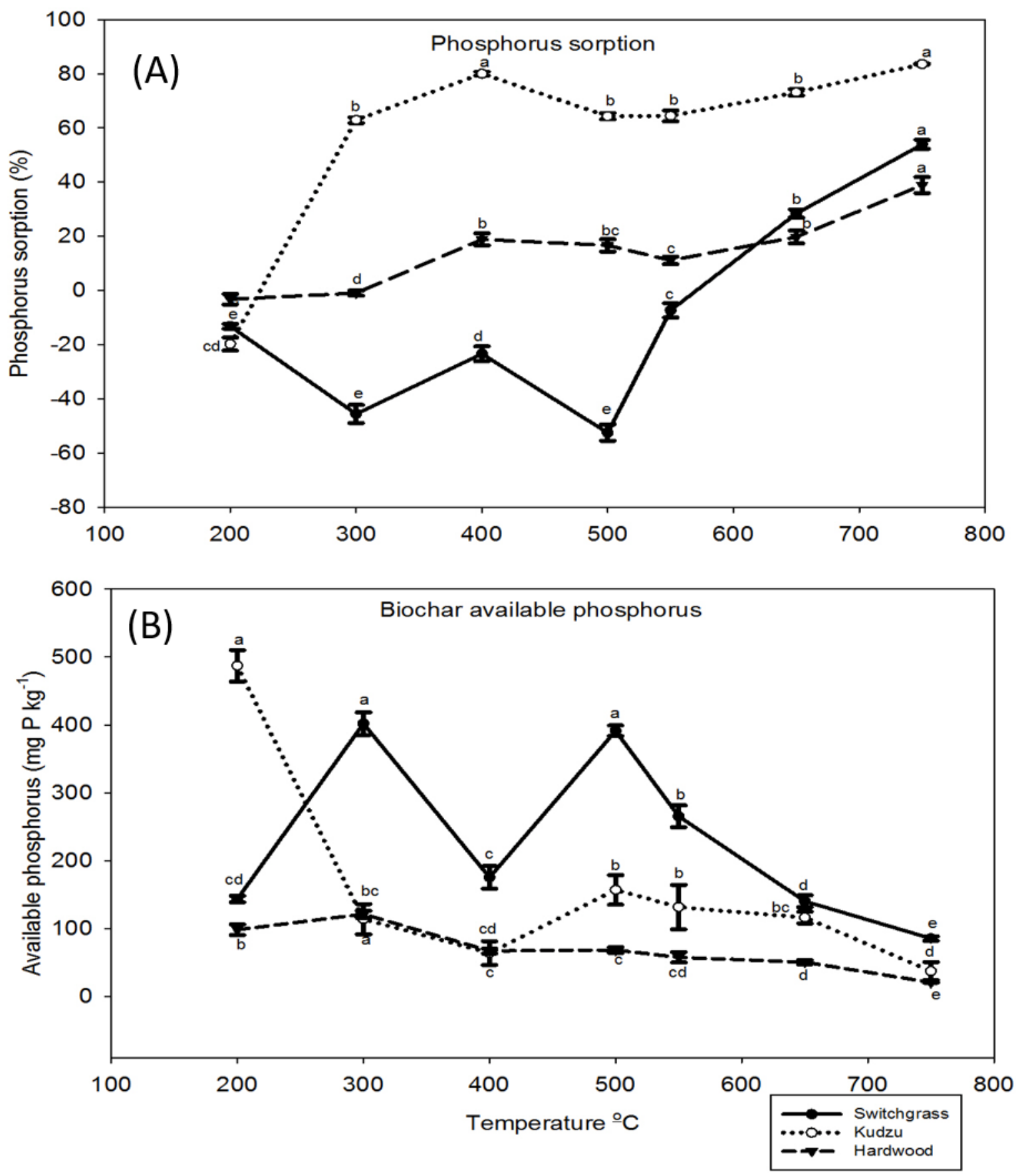
Fig. 6

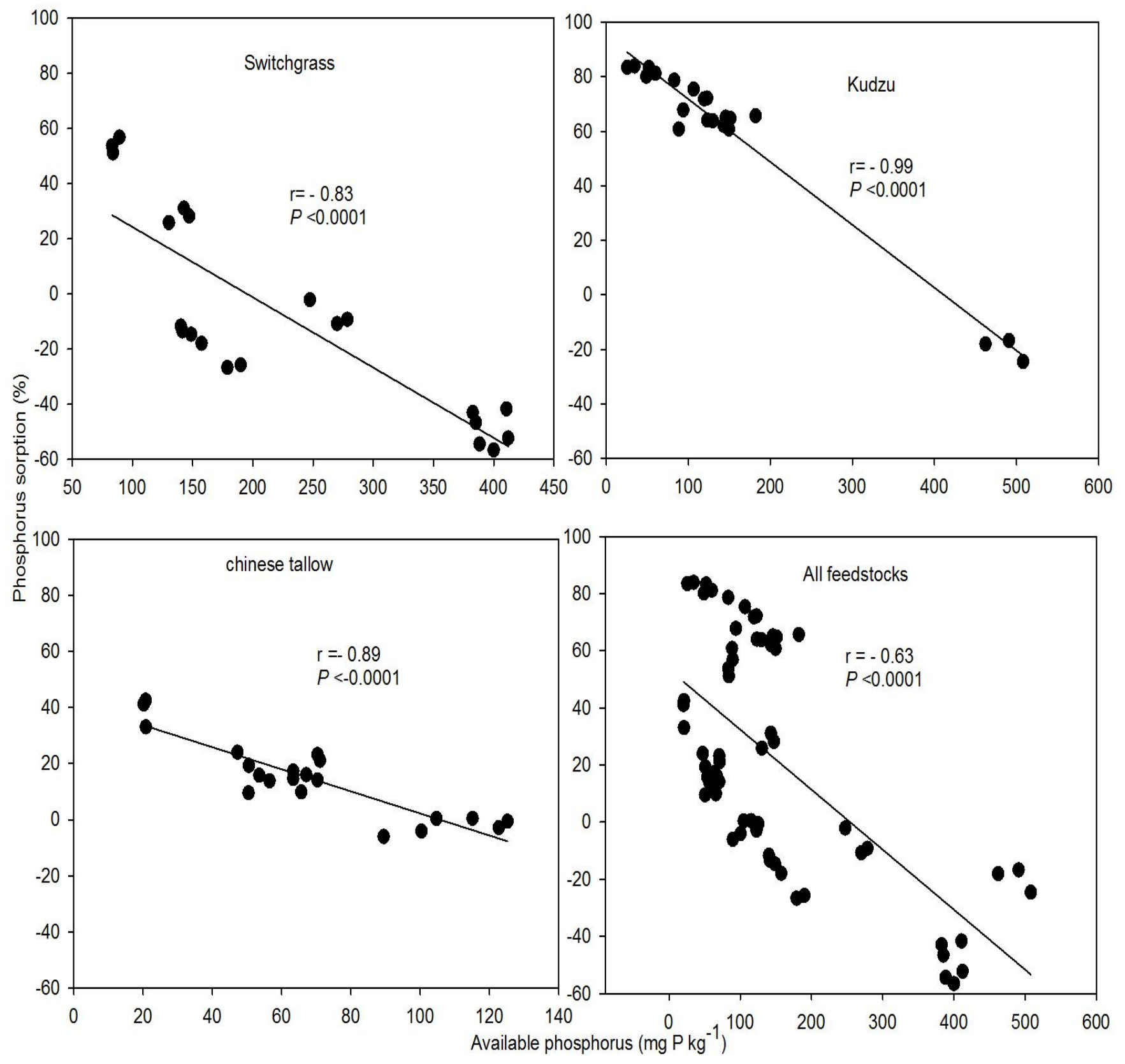


Fig. 7
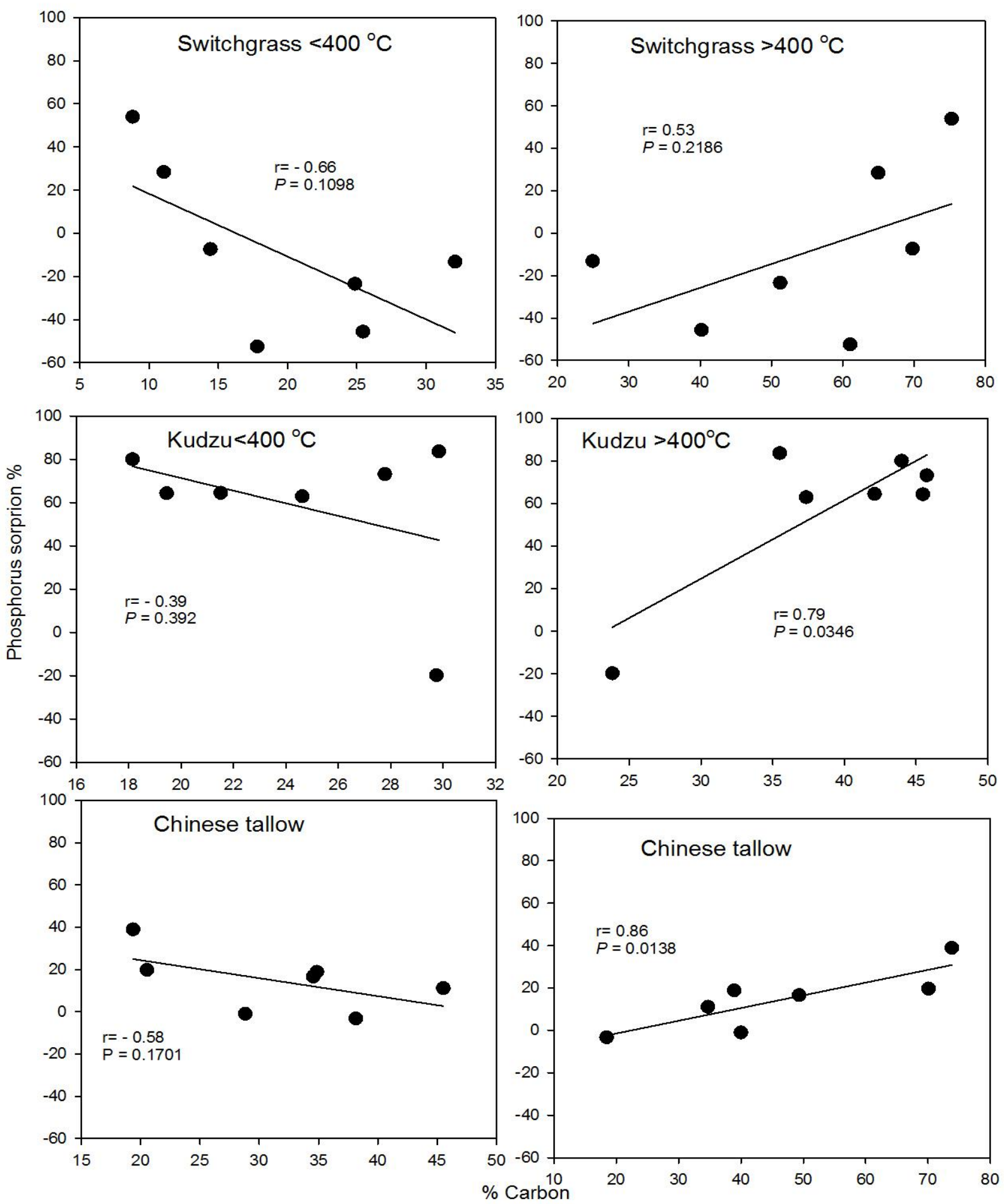
Fig. 8
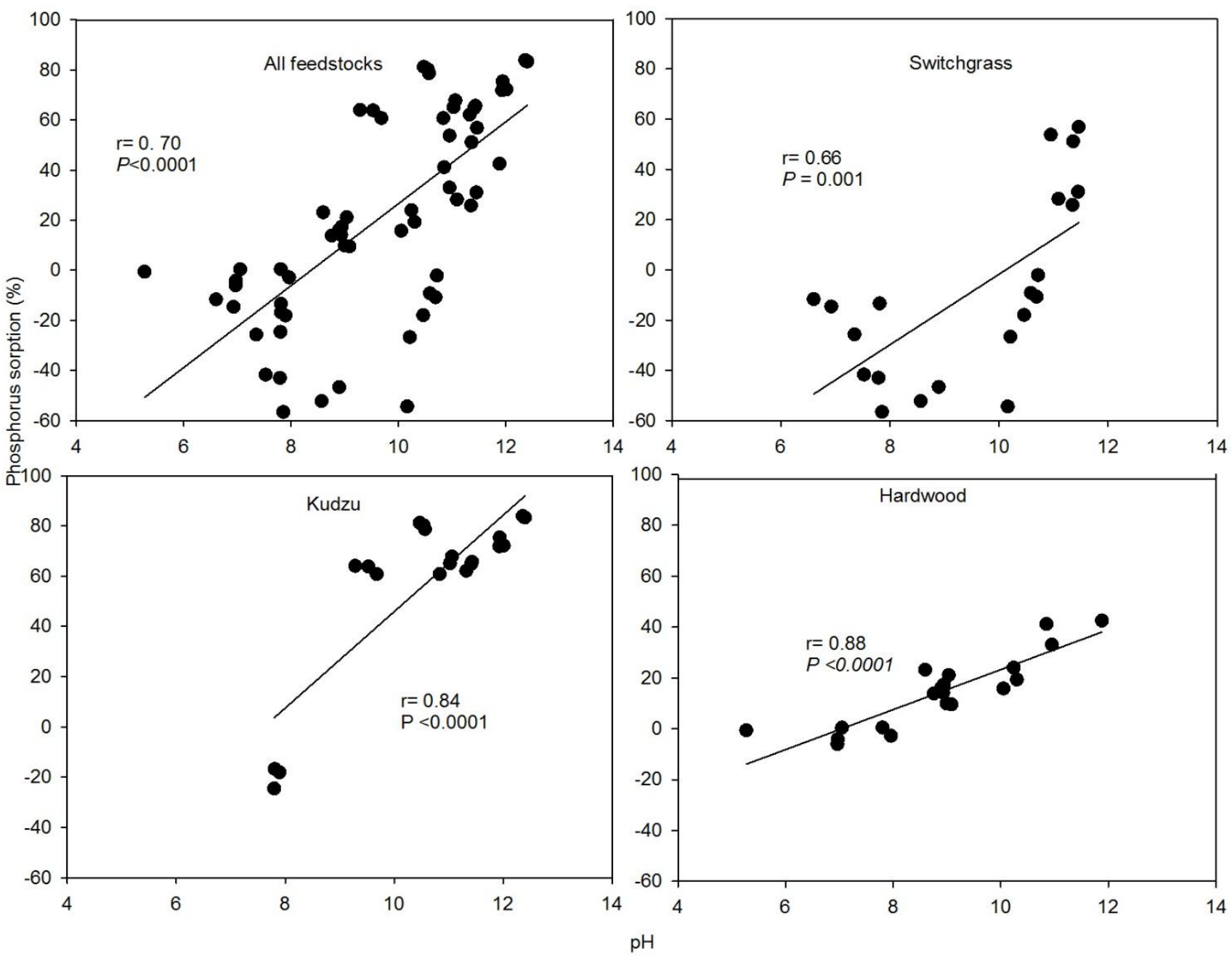